\title{
Evaluation Of Estrogen Level In Oral Contraceptive Pills Used By The Women With Cerebral Venous- Sinus Thrombosis
}

Abdolreza ghoreishi ${ }^{1}$, Ali Niksirat ${ }^{2 *}$, Hanieh Paydari ${ }^{3}$

${ }^{1}$ Assistant professor of neurology, Zanjan University of Medical Sciences, Zanjan, Iran.

${ }^{2}$ Resident of Internal Medicine, Tehran University of Medical Sciences, Iran

${ }^{3}$ General Practitioner, Tehran University of Medical Sciences, Iran

Introduction: Muslim women are not allowed to perform religious ceremonies in menstrual period. Some of them use oral contraceptive pills (OCPs) to delay menstruation, which can lead to cerebral venous - sinus thrombosis (CVST). Therefore, the incidence of CVST is significantly higher in Iranian women. Thrombosis incidence is directly related to estrogen level of OCPs. In this study, the estrogen level of OPCs was evaluated in a group of female CVST patients.

Methods: This study was conducted from 2010 to 2011, including two consecutive months of Ramadan in Zanjan Province of Iran. The remaining tablets of patients with CVST and OCP consumption history were analyzed by HPLC method.

Results: Of 32 female CVST patients, 27 patients had a history of OCPs consumption. 24 cases of them consumed LD. Analysis of LD tablets revealed normal level of estrogen except for one case.

Conclusion: Using contraceptive products among Muslim women in incorrect manner to delay menstruation should be considered by healthcare system. It is recommended to decrease amount of estrogen in OCPs till their contraceptive effect is unaffected.

Key words: Cerebral venous - sinus thrombosis, Oral Contraceptives, fasting, estrogen

DOI: 10.7575/aiac.abcmed.ca1.16

Published Date: February 2017

Peer-review is under responsibility of the 9th Iranian Stroke Congress.

Published by Australian International Academic Centre, Australia

This published work is open access under the CC BY license.

Available online at www.abcmed.aiac.org.au 